\title{
Idiopathic Pneumonia Syndrome
}

National Cancer Institute

\section{Source}

National Cancer Institute. Idiopathic Pneumonia Syndrome. NCI Thesaurus. Code C62590.

An inflammatory lung disease characterized by diffuse interstitial pneumonitis and alveolitis leading to interstitial fibrosis in the absence of an identifiable infectious agent. 